\title{
HELMINTHIASES IN MONTES CLAROS PRELIMINARY SURVEY
}

\author{
Rina Girard Kaminsky *
}

\begin{abstract}
A preliminary survey was conducted for the presence of helminths in the city of Montes Claros, M.G., Brazil. Three groups of persons were examined by the direct smear, Kato thick film and MIFC techniques; one group by direct smear and Kato only.

General findings were: a high prevalence of hookworm, followed by ascariasis, S. mansoni, S. stercoralis and very light infections with $T$. trichiura. $E$. vermicularis and $\mathrm{H}$. nana were ranking parasites at an orphanage, with some hookworm and $\mathrm{S}$. mansoni infections as well. At a pig slaughter house, the dominant parasites were hookworm and S. mansoni. Pig cysticercosis was an incidental finding worth mentioning for the health hazard it represents for humans as well as an economic loss. From the comparative results between the Kato and the MIF the former proved itself again as a more sensitive and reliable concentration method for helminth eggs, of low cost and easy performance.
\end{abstract}

\section{INTRODUCTION}

The following parasitological investigation was carried out from September 1973 to March 1974 in the city of Montes Claros, in the State of Minas Gerais, Brazil. Montes Claros is a fast developing regional center of education, industry and transportation, located in a section of the State characterized as the Northern Minas Drought Region. Montes Claros county is composed of the central city and 7 other districts with a county totat population of 116,464 . 85,072 reside in the urban area, while 31,392 form the rural population. In all there are 9 hospitals in the city, 5 general and 4 specialized. The Northern Minas Medical School was founded 5 years ago to provide physicians to meet the health needs of the whole region. The climate is hot and dry with few rains, from where the name of Drought Region is derived. Median temperature from September - March 1973 - 74 was of $200 \mathrm{C}$, with $71 \%$ humidity and a total annual precipitation of $1041.9 \mathrm{~mm}$ (Serviço Publico Federal, Estação de Montes Claros).
With the financial help of the newly formed Medical School and as a preliminary step in community surveys for parasites, selected methods were tested for suitability for the predominant types of specimens, technician skills necessary and laboratory conditions and equipment required. At the time of the study the only method used at the Medical School laboratory for fecal examination was the MIF (performed as taught by a Peace Corps Volunteer who trained the technicians). Specimens for routine examination came from the Charity Hospital (Santa Casa), and from Unidade Sanitaria de Saude. Two simple methods were tested besides the MIF: a direct smear and a Kato thick film. The direct smear technique was ini.oduced mainIy to acquaint the technicians with it as part of their training. It was also helpful in detecting Strongyloides larvae and protozoan trophozoites. The Kato will detect all common types of helminth eggs (not protozoa or Strongyloides larvae).

Besides studies of samples from Santa Casa and Unidade Sanitaria de Saude, and as a further

* Visiting Lecturer, Escola de Medicina do Norte de Minas, Montes Claros, Brazil.

Present Address: Lecturer, Department of Pathology, P.O. Box 30588, Nairobi. Kenya.

Submitted to publication on 11.11.1975. 
step in trying to recognize common parasitosis of the area, one orphanage (Lar das Crianças) and the workers at a pig slaughter house (Fabrica de Banhas Maisa) were studied for parasites.

\section{METHODS}

Direct smear. This was prepared by mixing a small amount of fresh feces on a drop of saline and mounting under a $22 \times 22$ cover-glass. Care was taken to make the preparation as uniform as possible, estimating a fecal volume of $2 \mathrm{mg}$. of feces on each on $e^{2}$. This volume was estimated by checking each smear under the microscope. When every particle of feces was seen individually and there was no clear space between them, the smear was considered good. In case of diarrheic stools, less saline was added to the sample. This method, as said before, was introduced for the first time in the laboratory as a useful and simple technique in general, as well as a fast and effective method for egg counts ${ }^{2},{ }^{4}$.

isato thick film. This method was followed step by step as described by Martin and Beaver ${ }^{8}$. All sciecimens were strained first through stainless steel bolting cloth (105 mesh) as it was found that too much fiber content in the feces inteifered otherwise:

1) A sample of fresh feces was stained and placed on a slide.

2) A strip of cellophane previously soaked in a mixture of glycerin and water 1:1 was pressed against it on an absorbent paper towel and feces spread to the size of the cellophane strip.

3) The smear was left at room temperature to clear about $\mathbf{4 5}$ minutes the time having been established by prior trial.

4) The entire smear was examined under $40 x$ magnification (scanning lens). Diarrheic stools were not examined by this method.

$M I F$. This had been the routine procedure used for fecal examination. MIF solution $A$ (dest. water, formaldehyde and merthioláte $1: 1000$ ) was mixed with solution B (iodine crystals, potassium iodine and dest. water) and kept in a large jar. A fresh fecal sample was mixed with MIF solution, soured on a cent-ifuge tube to an which ether was added and then agitated. After 5 minutes centrifugation, the supernatant was decanted and the sediment was examined under $100 \mathrm{X}$ magnification.

Anal Swabs. These were done on children at the orphanage to investigate $E$. vermicularis. The method was the scotch tape and the sample, taken early in the morning before cleaning ${ }^{1}$.

\section{GENERAL FINDINGS}

Table I summarizes the results of the $f \epsilon$ examinations. 177 samples from patients Santa Casa and Unidade Sanitaria were examir by 3 methods: direct, Kato and MIF. To routine exams of the 54 persons at the orphani (42 children and 12 adulst) the scotch t: method was added to investigate the presence E. vermicularis. This makes a total of 231 san les, out of which 66 were negative to methods, 72 had single infections and $93 \mathrm{r}$ mixed ones. At the pig slaughter iuuse, persons were examined by the direct smear a Kato only, finding 10 persons negative to bc methods.

Hookworm was the most common paras among the 177 patients of Santa Casa a Unidade Sanitaria 44\% (79 cases), with. me having light to moderate infections. $7(11 \%$ the infections) had a count above 25 eggs : direct smear $(27,83,25,80,61,67,61$ A. Iumbricoides presented 6 cases of heavy infi tion (4.8\%) according to egg counts of 116,14 $366,157,365$ and 549. 4.8\% had modera infections (6 cases) and $14.4 \%$ (18 cases) wer light with both fertile and unfertile eggs. In 30 the heavy infections the age recorded was 2, : and $3 \frac{1}{2}$ years old. S. mansoni infections were alse frequent. Most of the whipworm cases wer detected with either one or both of the concen tration methods, but almost invariably in ver low numbers of eggs per smear. S. stercoralis wa also present in significant numbers. In on instance 5 members of the same family wer infected, but the case was lost to follow-up.

The orphanage offered a very different pictu re. Ranking in prevalence were $E$. vermiculari and $H$. nana. Children one year old were alread) infected with $H$. nana. Hookworm was also pre valent, 15 cases of which 8 were adults.

At the slaughter house, hookworm and $S$. mansoni were the most commonly found infec tions. From the $2 \mathrm{~A}$. lumbricoides infections one had a count of 10 infertile eggs and the other 20 fertile eggs per direct smear.

It is of interest that of the 25 pigs slaughtered daily $10 \%$ were infected with Cysticercus cellulosae ${ }^{*}$. The meat was inspected by a representative of the Health Department and the whole infected carcasses were either disposed off by incineration

\footnotetext{
- Through a personal communication on 10-10-75 from the owner of the slaughter house, the infection rate has come down to $5 \%$, in a little more than one year time, due to newly introduced techniques to raise the pigs and the gradual education of the people.
} 
or used for processed products, as fertilizers or food for animals. The pig Ascaris recovered on several occasions were used for demonstration purposes at the Medical School. An attempt was made once to recover pig Trichuris, but without success.

Table II summarizes the comparative results between the Kato thick film and the MIF.

Of the 20 negative cases of hookworm by MIF 17 revealed 1.11 eggs in the whole Kato smear, while the other 3 had counts of 87,41 and 30 respectively. On the whole the Kato smear proved to be more sensitive than the MIF to detect other infections when they were very light.

\section{DISCUSSION}

Since this was a preliminary survey in an attempt to learn about parasite presence in the area of the Montes Claros, data of no other type were sought. Furthermore, the surveyed population was too small to provide firm conclusions on the degree of prevalence or endemicity of any for the helminths found. However, some points are worth considering.

It is worth noticing the presence of hookworm in all four different groups of persons, from very light to moderate and heavy infections in terms of eggs per direct smear. Six cases with high egg counts were all from hospitalized patients and although the causes of hospitalization were not recorded, it is not improbable to be due to hookworm related disease. According to a WHO report ${ }^{11}$ detectable anemia threshold in males and females appear with a count of $6,600-10,200$ eggs per gram (12-20 eggs per direct smear). In the above mentioned cases, the count ranged from $12,500-43,000$ eggs per gram (25-87 eggs per direct smear) a worm burden that cannot be without consequences to the host. Many cases, on the other hand, presented light infections, some only detectable on concentration techniques, which would not bear clinically on the patient but which cannot be overlooked or underestimated when assessing data of value in public health importance of soil transmitted helminths. In regard to $A$. lumbricoides only in 3 cases of heavy infection was the age recorded; as expected, they were children 2-31/2 years old an probably so were the other 3.

Beaver in $1952{ }^{3}$ made the observation that in regions where hookworm infection is hyperendemic, the incidence of ascariasis is generally low and conversely, when Ascaris is prevalent, hookworm infections are low or uncommon. The factors to consider in this case are the different types of soil prefered by each species of intestinal nematodes, together with relative moisture and optimal temperature. Ascaris eggs develop and survive better in shaded, damp soils containing clay and heavy loam, whereas sandy soils are better for infective hookworm larvae. Being ascariasis a household infection due to the constant pollution of the soil by toddlers, who in turn are the most heavily infected, it is not surprising to find viable Ascaris eggs in dooryards of infected families, specially when these are shaded and kept damp by dooryard drainage or household refuses. During the dry season, the infective eggs become relatively scarce and would only be found in a narrow zone around the entrance ways where dampness is maintained ${ }^{3}$. Transmission of hookworm in dry areas probably occurs during short periods of warm, rainfall season, when polluted soil would produce a very high degree of infectivity. It should be worth looking into this question in the Montes Claros area and assessing the endemicity of both helminths, together with $T$. trichiura by ways of determining the environemtal factors involved or physical properties of the soil.

It is not uncommon to find the ubiquitous pinworm in children, especially when living in institutional settings. This was also the case among children at the orphanage, probably due to cross infections among members. Such settings are also ideal for continueal transmission of $H$. nana once introduced, since it needs only one host to complete development and is easily transmitted from one child to the other. Beaver ${ }^{4}$ brought to attention that $H$. nana is one of the most common helminths found in people of arid regions. This association has not been yet adequately explained.

$S$. mansoni is endemic in many parts of Brazil, so it is not surprising to find it here again, which although a drought area, is irrigated by smalll affluents to the S. Francisco river, where the intermediate host could be found.

It is worth commenting on the findings of pig cysticercosis, which besides posing a threat to the health of the people, undoubtedly represents an economic loss. Attempts should be made to closely investigate the human-pig transmission looking for ways to interrupt it. Apparently the breeding occurs in low scale among many breeders, which may make the project more feasable.

The results on the comparative studies between the Kato and MIF techniques are not surprising. The excelence of the Kato has been reported each time it has been 
Table I - Helminths found most prevalent among different types of population

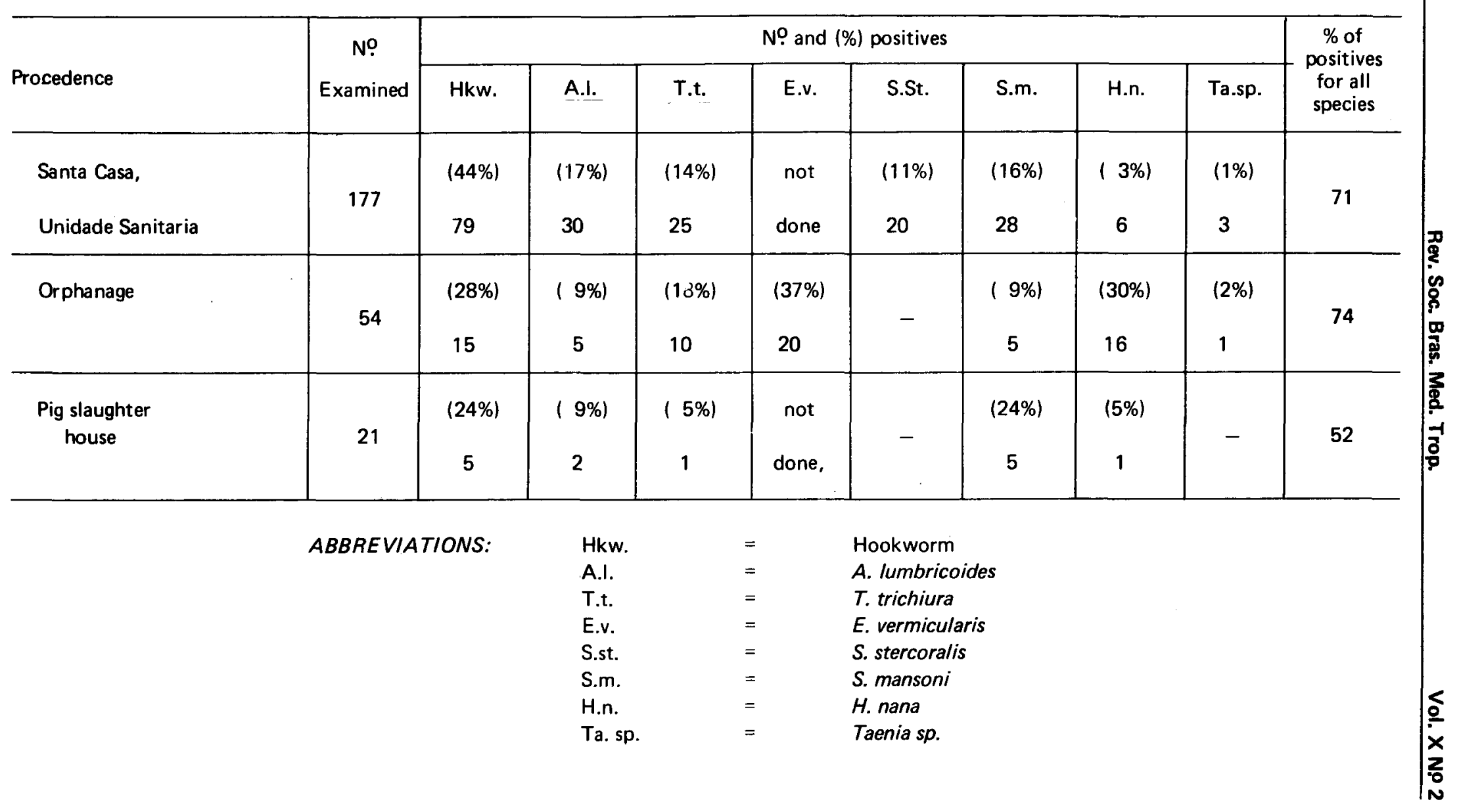


Table II - Sensitivity of the Kato thick film as compared to the MIF. Summary of 231 samples examined.

\begin{tabular}{l|c|c|c|c|c}
\hline \multirow{2}{*}{ Techniques } & \multicolumn{5}{|c}{ Numbers of specimens with eggs of } \\
\cline { 2 - 6 } & Hhw. & A.I. & T.t. & S.m. & H.n. \\
\hline Kato + MIF - & 20 & 4 & 14 & 6 & 2 \\
Kato - MIF+ & 3 & $1^{*}$ & 3 & & 1 \\
\hline
\end{tabular}

* infertile eggs and few in numbers.

used $^{5}, 6,7,8,9,10,12$. Kato showed more sensitivity to detect eggs specially in very light infections, which along with its low cost and easy performance, makes of it an ideal tool in epidemiological surveys, where it has mainly been used for. It would be of interest to test it in the routine laboratory, in combination with another method for larvae and protozoa that are not detected in Kato. The direct smear, surprisingly, is not used in any of the operating laboratories of Montes Claros. Not only is it a necessity tool in the routine diagnosis of protozoa trophozoites missed otherwise - when no staining is used - but it is of advantage when egg counts are required. Many times larvae are easier to identify in a fresh fecal smear, after immobilizing them for study with heat or a drop of Lugol's solution.

Many other surveys have been conducted in Brazil in areas where climatic conditions present are quite different from the one studied now. The main objective of this study was to determine the kinds of parasites to be emphasized in the training of physicians for that area, as well as to prepare the way for small, interesting community health projects with the students.

\section{ACKONWLEDGEMENTS}

Dr. Itagiba de Castro Filho, Dean of the Northern Minas Medical School is sincerely thanked for financial assistance and cooperation during the investigation. The author is indebted to Dr. Paul C. Beaver, Tulane University, for encouragement and constructive criticism in the preparation of this work, and reading of the manuscript.

\section{RESUMO}

Um estudo preliminar sobre helmintos foi feito na cidade de Montes Claros, MG, Brasil. Três grupos de pessoas foram examinados pelos métodos direto, de Kato e do MIF e um grupo pelos métodos direto e Kato exc/usivamente. Encontrou-se uma alta prevalência de necatorose, seguindo-se ascaríase, S. mansoni, S. stercoralis, e infecções leves pelo T. trichiura. E. vermicularis $e \mathrm{H}$. nana foram os parasitos mais prevalentes num orfanato, com alguns casos de infeção pelo Necator $e \mathrm{~S}$. mansoni. Cisticercose dos suinos foi achado incidental e é importante ser mencionada devido ao perigo que representa no plano da Saúde Pública, bem como pela perda econômica que produz. Discutiu-se brevemente a importância do solo na transmissão dos helmintos num clima quente e seco. Da comparação dos métodos de Kato e MIF, o primeiro demonstrou ser o método mais sensível para ovos de helmintos, de baixo custo e fácil preparo. 


\section{REFERENCES}

1. BEAVER, P.C. Methods of pinworm diagnosis. Am. J. Trop. Med. 29: 577-587, 1949.

2. BEAVER, P.C., The standardization of fecal smears for estimating egg production and worm burden. J. Parasit, 36: 451-456, 1950.

3. BEAVER, P.C. Observations on the epidemiology of ascariasis in a region of high. hookworm endemicity. J. Parasit., 38:445-453, 1952.

4. BEAVER, P.C. Control of soil-transmitted helminths. WHO Public Health Papers n? 10,1961

5. CALLOT, J., M. KREMER, F. MILTGEN, Note a propos de l'excellente techinique coproloqyque de Kato. Bull. Soc. Path. Exot. 62:747-750, 1969.

6. KATZ, N. COELHO, M. \& PELLEGRINO, J. Evaluation of Kato's quantitative method through the recovery of $S$. mansoni eggs added to human feces, J.Parasit. $56: 1032-1033,1970$.
7. KOMIYA, Y., \& KOBAYASHI, A. (As taken from Martin and Beaver, 1968).

8. MARTIN, L. \& BEAVER, P.C. Evaluation of Kato thick smear technique for quantitative diagnosis of helminth infections. Am. J. Trop. Med. Hyg., 17:382-391, 1968

9. MARTIN, L., Hookworm in Georgia. I. Survey of intestinal helminth infections and anemia in rural school children. Am. S. Trop. Med. Hyg. 21: 919-929, 1972.

10. ROUGEMONT, A., J. ROMAIN, C. DENOIX \& QUILICl, M. Prevelence des helminthiases intestinales dans la region de Bamako, Mali. Med. Trop. 34: 29-36, 1974

11. WHO Expert Committee on Helminthiases, Wid. Hith. Org. Techn. Rep. Ser., No 277:14, 1964.

12. ZAMAN, V., \& CHEONG, C.H.A comparison of Kato thick smear technique with zinc sulfate flotation method, for the detection of helminth ova in feaces. Trans. Roy. Soc. Trop. Med. Hyg., 61:751, 1967. 